\title{
Ensino universitário, corporação e profissão: paradoxos e dilemas brasileiros'
}

Educação superior e matriz profissionalizante

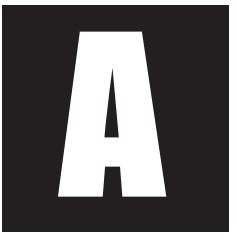

relevância e o conteúdo do ensino superior no Brasil estão amarrados à decisão pregressa de que a educação superior existe para oferecer educação profissional. Esta decisão, no rastro de modelagem francesa ancestral, exige que os estudantes brasileiros tenham sua visão de mundo simplificada pelo que pode ser chamado de profissionalização precoce. ${ }^{2} \mathrm{Ou}$ seja, desde os 15/16 anos, os estudantes do ensino médio precisam começar a optar pela profissão futura, de modo a definir o curso de graduação a ser realizado e, assim, melhor se prepararem para os vestibulares - principal-

* Coordenador do Observatório Universitário, Ph. D. em Ciência Política, U.C. Berkeley. Atualmente, Presidente do Conselho Nacional de Educação (CNE) e exerce a função de Pró-Reitor de Planejamento e Desenvolvimento da Universidade Candido Mendes (UCAM). Brasil.

** Pesquisadora do Observatório Universitário da Universidade Candido Mendes e do Observatório Universitário. Brasil.

1 Versão inicial debatida no III Simpósio Nacional de Direito Educacional, Centro de Extensão Universitária, CEU, S. Paulo, 25/8/2006. Os dados foram também discutidos no 30* Encontro Anual da ANPOCS, Caxambu, M.G., 25/10/2006.

$2 \mathrm{O}$ tema da profissionalização precoce no Brasil foi objeto de estudo em Nunes, Edson, Nogueira, André e Molhano, Leandro. Futuros Possíveis, Passados Indesejáveis: Selo de Qualidade da OAB, Provão e Ensino Superior no Brasil. Rio de Janeiro, Editora Garamond, 2000. 
mente aqueles que almejam ingressar em instituições públicas, cujo acesso é densamente competitivo.

Portanto, desde o ensino médio, pelo menos, inicia-se um processo de restrição da "visão de mundo" das gerações futuras, tornando-as candidatas à profissão antes de serem candidatas ao saber. Ao ingressarem nas instituições de ensino superior, tendo vindo, em geral, de um ensino médio decepcionante, ${ }^{3}$ salvo as exceções de elite de praxe, nossos estudantes orientam-se por uma matriz profissionalizante de ensino, deixando de lado a formação mais abrangente, humanística, histórica, social... enfim a educação.

A educação superior brasileira ainda está amarrada à definição das 43 profissões regulamentadas. Para se ter uma idéia do que representam esses números, em 2004, os cursos/programas de graduação vinculados às profissões regulamentadas respondiam por $67,07 \%$ do total de 18.644 cursos existentes (Tabela 1). Quando se analisa o número de alunos matriculados naquele ano, verifica-se que, do total de 4.163 .733 alunos, $79,67 \%$ (3.317.158 alunos), estavam matriculados em cursos de graduação vinculados às profissões regulamentadas. ${ }^{4}$

\footnotetext{
3 Como evidenciado pelos resultados do Sistema de Avaliação do Ensino Básico (SAEB).

4 Registre-se, ainda, nesse sentido, que, em setembro de 2005, estavam em tramitação no Congresso 73 propostas de regulamentação de profissões, das quais 18 referidas a profissões de nível superior (aí consideradas profissões como a de acupunturista cuja formação só é oferecida em nível de especialização, para graduados em fisioterapia e medicina). Observe-se, ainda que, curiosamente, das 43 profissões de nível superior regulamentadas ${ }^{4}, 10$ não estão incluídas nas 46 Diretrizes Curriculares em exame no CNE e/ou já aprovadas e homologadas (conforme informações disponíveis no sitedo CNE em 15.09.05). São elas: agrimensor, atuário, economista doméstico, engenheiro de segurança, estatístico, geólogo, meteorologista, relações públicas, e treinador de futebol, além de tecnólogo (nas áreas submetidas à regulamentação e fiscalização instituídas pela Lei 5.194, de dezembro de 1966, quais sejam: agronomia, engenharia civil, engenharia elétrica, engenharia mecânica, engenharia de minas e engenharia química)
} 
Tabela 1 - Profissões Regulamentadas de Nível Superior, Brasil 2004

\begin{tabular}{|c|c|c|c|c|}
\hline \multirow[t]{2}{*}{ Nome do Curso/Programas } & \multicolumn{2}{|c|}{ Cursos/Programas } & \multicolumn{2}{|c|}{ Matrículas } \\
\hline & Total & $\%$ & Total & $\%$ \\
\hline Total Brasil & 18.644 & $100 \%$ & 4.163 .733 & $100,0 \%$ \\
\hline Regulamentadas & 12.505 & $67,1 \%$ & 3.317 .158 & $79,7 \%$ \\
\hline 1 Administrador & 1.734 & $9,3 \%$ & 620.718 & $14,9 \%$ \\
\hline 2 Advogado & 729 & $3,9 \%$ & 533.317 & $12,8 \%$ \\
\hline 3 Agrimensor & 10 & $0,1 \%$ & 1.660 & $0,0 \%$ \\
\hline 4 Arquiteto & 180 & $1,0 \%$ & 47.675 & $1,1 \%$ \\
\hline 5 Arquivista & 9 & $0,0 \%$ & 1.599 & $0,0 \%$ \\
\hline 6 Assistente Social & 161 & $0,9 \%$ & 36.073 & $0,9 \%$ \\
\hline 7 Atuário & 13 & $0,1 \%$ & 1.771 & $0,0 \%$ \\
\hline 8 Bibliotecário & 36 & $0,2 \%$ & 6.894 & $0,2 \%$ \\
\hline 9 Biólogo & 507 & $2,7 \%$ & 91.491 & $2,2 \%$ \\
\hline 10 Biomédico & 54 & $0,3 \%$ & 6.711 & $0,2 \%$ \\
\hline 11 Contabilista & 763 & $4,1 \%$ & 162.150 & $3,9 \%$ \\
\hline 12 Economista & 266 & $1,4 \%$ & 59.020 & $1,4 \%$ \\
\hline 13 Economista Doméstico & 9 & $0,0 \%$ & 1.308 & $0,0 \%$ \\
\hline 14 Enfermeiro & 415 & $2,2 \%$ & 120.851 & $2,9 \%$ \\
\hline 15 Engenheiro & 971 & $5,2 \%$ & 247.748 & $6, \%$ \\
\hline 16 Engenheiro Agrônomo & 130 & $0,7 \%$ & 31.522 & $0,8 \%$ \\
\hline 17 Engenheiro de Segurança $^{1}$ & - & $-\cdots$ & - & ---- \\
\hline 18 Estatístico & 26 & $0,1 \%$ & 4.628 & $0,1 \%$ \\
\hline 19 Farmacêutico & 237 & $1,3 \%$ & 61.277 & $1,5 \%$ \\
\hline 20 Fisioterapia & 339 & $1,8 \%$ & 95.749 & $2,3 \%$ \\
\hline 21 Fonoaudiólogo & 99 & $0,5 \%$ & 13.123 & $0,3 \%$ \\
\hline 22 Geógrafo & 425 & $2,3 \%$ & 54.187 & $1,3 \%$ \\
\hline 23 Geólogo & 18 & $0,1 \%$ & 3.188 & $0,1 \%$ \\
\hline 24 Jornalista & 605 & $3,2 \%$ & 187.701 & $4,5 \%$ \\
\hline 25 Médico & 136 & $0,7 \%$ & 64.965 & $1,6 \%$ \\
\hline 26 Meteorologista & 6 & $0,0 \%$ & 801 & $0,0 \%$ \\
\hline 27 Museólogo & 2 & $0,0 \%$ & 174 & $0,0 \%$ \\
\hline 28 Músico & 84 & $0,5 \%$ & 6.970 & $0,2 \%$ \\
\hline 29 Nutricionista & 201 & $1,1 \%$ & 38.929 & $0,9 \%$ \\
\hline 30 Odontologia & 174 & $0,9 \%$ & 46.039 & $1,1 \%$ \\
\hline 31 Orientador Educacional $^{2}$ & - & $-\cdots$ & - & ---- \\
\hline 32 Professor $^{3}$ & 2.478 & $13,3 \%$ & 389.591 & $9,4 \%$ \\
\hline 33 Profissional de Educação Física & 469 & $2,5 \%$ & 136.605 & $3,3 \%$ \\
\hline 34 Psicólogo & 272 & $1,5 \%$ & 94.501 & $2,3 \%$ \\
\hline 35 Químico & 248 & $1,3 \%$ & 33.190 & $0,8 \%$ \\
\hline
\end{tabular}


Continuação

\begin{tabular}{|l|c|c|c|c|}
\hline Nome do Curso/Programas & \multicolumn{1}{c|}{ Cursos/Programas } & \multicolumn{2}{c|}{ Matrículas } \\
\hline \multicolumn{1}{|c|}{ Total Brasil } & Total & $\%$ & Total & $\%$ \\
\hline \multicolumn{1}{|c|}{ Regulamentadas } & $\mathbf{1 2 . 5 0 5}$ & $\mathbf{1 0 0} \%$ & $\mathbf{4 . 1 6 3 . 7 3 3}$ & $\mathbf{1 0 0 , 0} \%$ \\
\hline 36 Relações Públicas & 19 & $0,1 \%$ & $\mathbf{3 . 3 1 7 . 1 5 8}$ & $\mathbf{7 9 , 7 \%}$ \\
\hline 37 Secretário & 144 & $0,8 \%$ & 17.829 & $0,0 \%$ \\
\hline 38 Sociólogo & 108 & $0,6 \%$ & 20.071 & $0,5 \%$ \\
\hline 39 Tecnólogo & 207 & $1,1 \%$ & 25.839 & $0,6 \%$ \\
\hline 40 Terapeuta Educacional & 39 & $0,0 \%$ & 5.385 & $0,1 \%$ \\
\hline 41 Treinador de Futebol & - & $0,0 \%$ & - & $0,0 \%$ \\
\hline 42 Veterinário & 119 & $0,0 \%$ & 34.657 & $0,8 \%$ \\
\hline 43 Zootecnista & 63 & $0,0 \%$ & 9.308 & $0,2 \%$ \\
\hline Não regulamentadas & 6.139 & $32,9 \%$ & 846,575 & $20,3 \%$ \\
\hline
\end{tabular}

Fonte: MEC/Inep, Censo da Educação Superior, 2004.

Notas:

1Não foi localizado nem um curso com essa denominação ou com denominação equivalente.

${ }^{2}$ Computado junto com professor tendo em vista o Decreto n\} 72.846 que regulamenta. ${ }^{3}$ Considera os alunos de pedagogia e os de formação de professor.

${ }^{4}$ Mecânica, mineração e extração nos termos da Lei 5.194/66 que dispõe sobre o exercício dos tecnólogos.

Esta matriz profissionalizante da educação superior é, em grande medida, decorrência da forte influência que as corporações profissionais exercem sobre os currículos dos cursos de graduação. ${ }^{5}$ Isso não quer dizer que o ensino superior não deva levar em consideração os conteúdos consi-

5 Não se pode perder de vista que, tradicionalmente, as corporações são consultadas pelo Ministério de Educação, pela Secretaria de Ensino Superior e pelo Conselho Nacional de Educação, para a preparação dos currículos, normas e diretrizes curriculares. O Edital 04/97, através do qual se iniciou o processo de discussão das diretrizes curriculares, convocou as IES a apresentarem a definição das diretrizes que seriam elaboradas pelas Comissões de Especialistas da SESu/MEC. O Edital afirma que "é desejável a integração das IES com as sociedades científicas, ordens e associações profissionais, associações de classe, setor produtivo e outros setores envolvidos, através de seminários, encontros, workshopse reuniões, de forma a garantir Diretrizes Curriculares articuladas tanto às reformas necessárias à estrutura da oferta de cursos de graduação, quanto aos perfis profissionais demandados pela sociedade". 
derados necessários para a formação de um profissional. Ao contrário, uma das exigências da educação superior é, também, formar bons profissionais. A questão é saber equacionar quando e em quem focar a educação profissionalizante, sabendo equacioná-la com uma formação geral mais ampla. ${ }^{6}$ Mas, como, no Brasil, profissão é assunto de Estado e está vinculada à lei corporativa, acaba-se exigindo da educação superior o título de bacharel nesta ou naquela profissão. Ressaltem-se, por exemplo, as imposições que as corporações fazem para o exercício profissional. Para que uma pessoa possa participar como técnico de uma empresa em uma concorrência pública, é preciso que ela esteja inscrita na entidade corporativa pertinente. ${ }^{7}$ Não só ela, mas a empresa também precisa estar inscrita no órgão, com suas taxas em dia. Esse tipo de imposição apenas mostra como a educação superior brasileira está mais associada à vida corporativa do que à vida educacional.

Formam-se, no Brasil, jovens-bacharéis, "doutores" em nosso linguajar, que mal sabem escrever, desconhecem história e literatura, estão distanciados dos grandes temas nacionais e internacionais, das angústias e heranças do nosso mundo e de nosso país. Freqüentemente, para dar um exemplo, ficamos surpreendidos quando nos deparamos com um texto universi-

6 A esse respeito ver, A outra reforma universitária para a sociedade do conhecimento, Edson Nunes e Leandro Molhano. In: VELLOSO, João Paulo dos Reis(org). Novo Modelo de Educação para o Brasil, José Olympio Editora, Rio, 2004.

7 A concorrência pública aqui mencionada é uma das modalidades de licitação prevista no artigo 22 , inciso I, da Lei 8.666/93. Está definida no $§ 1$ 을 do referido artigo como sendo uma "modalidade de licitação entre quaisquer interessados que, na fase inicial de habilitação preliminar, comprovem possuir os requisitos mínimos de qualificação exigidos no edital para execução de seu objeto." Inicialmente, para participar do processo de licitação, é necessário o cumprimento de requisitos para que o participante seja considerado habilitado para concorrer as fases seguintes do processo. A habilitação envolve a comprovação de aptidão jurídica, da qualificação técnica, econômica, financeira, da regularidade fiscal de cumprimento do disposto no inciso XXXIII do artigo 7음 da CR/ 88. Os documentos que servirão para comprovar tais aptidões estão devidamente arrolados na Lei $8.666 / 93$, nos artigos 28 e seguintes. No caso da comprovação de habilitação técnica, o artigo 30 da lei em comento exige o registro e a inscrição na entidade profissional competente. 
tário bem escrito, uma monografia escorreita, uma dissertação de mestrado ou tese de doutorado bem apresentada. Surpreendemo-nos simplesmente porque saber escrever passou a ser algo excepcional, e não a mais rotineira obrigação do universitário brasileiro.

Ressalte-se aqui certa contradição: a educação profissionalizante acaba estando na contramão das exigências de um mercado de trabalho moderno, complexo e rotativo. Atualmente, grande parte do trabalho nas diversas ocupações e profissões modernas envolve justamente habilidades básicas como falar e escrever muito bem, preparar bons relatórios, ter conhecimento de informática, possuir raciocínio lógico quantitativo, falar e ler uma segunda língua. Um ensino não profissionalizante poderia permitir a formação dos estudantes nessas habilidades, além de proporcionar formação histórica e cultural da humanidade, ciências sociais e ciências. Amarrada a um currículo profissionalizante, a educação superior acaba descuidando-se da preparação dos estudantes para um mundo complexo, no qual as profissões tornam-se obsoletas rapidamente e é freqüente a mudança de emprego e de ocupações ao longo da vida profissional. ${ }^{8}$

A discussão acima leva a uma reflexão sobre a necessidade de existência de uma educação superior funcionalmente diferenciada e/ou especializada, que permitiria, por meio de um processo permanente de educação, várias opções complementares de formação. ${ }^{9}$ Essa diferenciação possibilitaria, por exemplo, o estabelecimento da educação universitária stricto

8 Discussões sobre a formação da educação superior e sua vinculação com o mercado de trabalho moderno pode ser encontrada em Brennan etal. What Kind of University? International Perspective on Knowledge, Participation and Governance. London: The Society for Research into Higher Education, Open University Press, 1999; Losco, Joseph e Life, Brian (Org.) Higher Education in Transition: the Challenges of the New Millennium. Westport, Connecticut: Bergin \& Garvey, 2000; O'Brien, George. All the Essential Half-Truths about Higher Education. Chicago: The University of Chicago Press, 1998.

9 Parte do argumento que se segue foi desenvolvido em Nunes, Edson et al. Teias de Relações Ambíguas: regulação e ensino superior. Brasília: Inep, 2002; 
sensu, sem preocupação com as determinações conjunturais/profissionais do mercado sobre a composição do perfil do educando, o que recomendaria a existência de bacharelados de natureza mais genérica, desligada das pautas profissionais-legais. Enquanto não houver um desligamento efetivo da matriz corporativa, não se terá constituído completamente a idéia de Universidade no Brasil. De certa forma, inexistem universidades no país, já que todas não passam de uma federação, ou arquipélago, de escolas profissionalizantes, com seu próprio recorte disciplinar essencialmente aplicado. Uma educação universitária ao nível da graduação deveria estar associada à diversidade de campus, pesquisa e pós-graduação em nível de doutorado, fazendo das "universidades" instituições basicamente de orientação científica, humanista e de estudos clássicos. ${ }^{10}$

Assim como os bacharelados genéricos se acoplariam mais facilmente, pela ausência do lamentável vezo profissionalizante atual, à atividade científica da pós-graduação, seria também importante que, no contexto de outras IES, que não universidades, se oferecessem graduações mais curtas, orientadas para ocupações, tal como exemplificado pelos cursos superiores de formação específica, os cursos seqüenciais, em regime de extinção, e pelos atuais cursos de tecnólogos. ${ }^{11}$ Por fim, poder-se-ia, igualmente, admitir

10 Para uma discussão a respeito ver Menezes, Luiz Carlos de. Universidade sitiada. São Paulo: Editora Fundação Perseu Abramo, 2000. No tema da universidade de pesquisa, em perspectiva comparada, ver Burton R. Clark (Ed.), The Research Foundations of Graduate Education: Germany, Britain, France, United States, Japan, University of California Press, Berkeley, 1993. Importante reflexão crítica sobre o modelo de pesquisa na pós-graduação está em Chriss Golde, George Walker (Eds.) Envisioning the Future of Doctoral Education: Preparing Stewards of the Discipline, The Carnegie Foundation for the Advancement of Teaching, Jossey-Bass, San Francisco, 2006

11 A relação de ensino universitário com ensino profissional não é simples, inclusive desde o ponto de vista da fundamentação curricular, mesmo em sistemas nos quais a separação é tida como aparente. Importante discussão está em Derek Bok, Our Underachieving Colleges: A Candid Look at How Much Students Learn and Why they Should be Learning More, Princeton University Press, Princeton, 2006. Observe-se, ademais, a reflexão de Harold Shapiro em A Larger Sense of Purpose: Higher Education and Society, Princeton U. Presss, 2005 : "Does professional education stand on the peripehery of the "real university" How does a liberalarts education relate do 
a existência de escolas pós-graduadas ligadas a profissões, tais como Medicina, Direito, Engenharia, bem eventuais MBAs de verdade- e não a contrafação que recebeu tal apelido no Brasil— isto é, programas de mestrado profissionalizantes voltados para a administração de negócios e economia empresarial. ${ }^{12}$

A necessidade de se discutir o ensino superior, fora dos parâmetros profissionais-corporativos, poderia ser acompanhada por uma verdadeira preocupação com a massificação necessária da educação superior. Deveria, no entanto, estar associada ao tema da eqüidade e igualdade de oportunidades, já que a educação universitária -aquela não profissionalizante-tenderia a atrair estudantes com menor preocupação imediata com o mercado de trabalho, naturalmente melhor posicionados economicamente, enquanto a educação profissionalizante atrairia aqueles mais premidos pela neces-

a professional education? My two conclusions: Professional education does not now and neverdid stand on the periphery of the university, and the basic aims of professional education are startingly similar to the aims of a liberalarts education. Indeed, the most valuable part of education for nay learned profession is thataspect that teaches future professionals do think, read, compare, discriminate, analyze, formjudgments, and generally enhance their mental capacity to confront the ambiguities and enigmas of the human condition. After all, a learned profession is in parta mode of culturalexplanation and socia/ understanding. " Pag..113. Sobre a diversidade institucional e a importância da mobilidade entre educação profissional e educação universitária, como pilar do sistema universitário, ver de Cohen, Arthur e Brawer, Florence. The American Community College. San Francisco: Jossey Bass, 1996.

12 A (re) configuração dos cursos de graduação, não apenas em consonância com o que se observa em outros países, mas também no sentido de melhor atender à crescente demanda por uma formação fora dos padrões profisisonais-corporativos, tem sido amplamente discutida nos trabalhos do Observatório Universitário. Além dos já citados Teias de Relações Ambíguas e Futuros Possíveis, veja-se a respeito Corporações, Estado e Universidade: O Diálogo Compulsório sobre a Duração de Cursos Superiores no Brasil, Edson Nunes, André Nogueira e Leandro Molhano, fevereiro de 2003; Mensuração dos Conteúdos Acadêmicos da Educação Superior, André Magalhães Nogueira, Edson Nunes e Helena Maria Barroso, abril de 2005; Os Desafios da Universidade Brasileira neste Início de Século e a Formação de nossas Elites, Edson Nunes, agosto de 2005; A Reforma que não houve, Edson Nunes e Leandro Molhano, abril de 2006. Publicado, sob o título "A Reforma Universitária no Quadro-Negro", em Custo Brasil - Soluções para o Desenvolvimento, ano 1, no. 2, abril/maio de 2006. 
sidade de trabalhar, o que faria com que a massificação do ensino superior gerasse, de forma não desejada, hierarquias internas e externas próprias, de modo a separar, simbólica e praticamente, as "elites" das "massas". ${ }^{13}$

De toda sorte, ao lado da afirmação de que ainda não existe ensino universitário no Brasil, apenas ensino profissionalizante, registre-se também que "embora elitizado em suas características socioeconômicas, tendo o setor privado sido capaz de receber proporção maior de elite, o ensino superior brasileiro mais se parece, educacionalmente, por conta de seus objetivos e características essenciais, com os community collegesamericanos, que são faculdades essencialmente não-elitistas, de dois anos, destinadas ao adestramento ocupacional dos estudantes, caracterizados por muitos cursos noturnos, de dedicação parcial, ensino essencialmente profissionalizante. No nosso caso, community colleges perdulários, de quatro anos. ${ }^{14}$

\section{Contradições: formação profissionalizante e mercado de trabalho}

Apenas 6,37\% da população com 23 anos ou mais de idade, no Brasil, tem educação formal de nível superior. A situação do Brasil em relação aos países membros da OCDE é, no mínimo, preocupante. A média desses países é de 22\% da população adulta com ensino superior completo (Gráfico 1).

13 - O tema da equidade e excelência educacional, com referência comparativa, pode ser buscado em Willian Bowen, Martin Kursweil, Eugene Tobin, Equity and Excellence in American Higher Education, University of Virginia Press, 2005. Sobre universidades e formação de elites, ver a análise de Ross Gregory Douthat, Privilege: Harvard and the Education of the Ruling Class, Hyperion, N.York, 2005. Já pelo lado estudantil, é imperdível o depoimento do agora famoso escritor de mistérios jurídicos, Scott Turow sobre sua vida de estudante na faculdade de Direito de Harvard: One L.: The Turbulent True Story of a First Year at Harvard Law School, Warner Books, N.York, 1977 e 988

14 - Em Edson Nunes e Leandro Molhano, "A outra reforma universitária: para a sociedade do conhecimento" in João Paulo dos Reis Velloso e Roberto Cavalcanti de Albuquerque, Novo Modelo de Educação para o Brasil, José Olympio Editora, Rio, 2004, p. 152. 


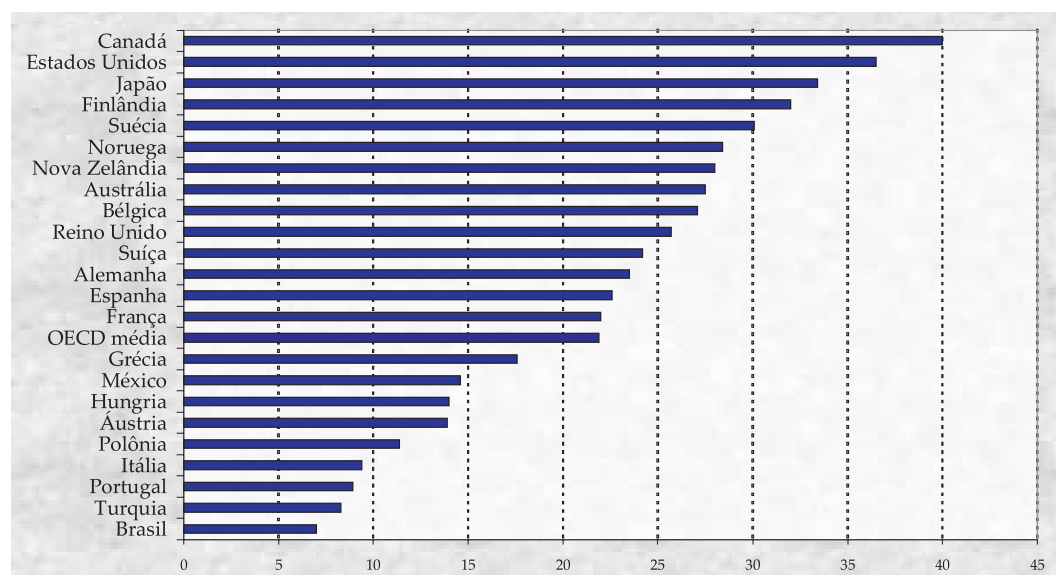

Gráfico 1 - Porcentagem da população adulta com ensino superior.

Fonte: OECD. Factbook 2006. Economic, Enviromental and Social Statistics. Brasil: IBGE, Censo Demográfico.

A significativa supremacia quantitativa de certas áreas de formação também se reflete, como não poderia deixar de ser dado o nosso modelo de ensino, no contingente de formados: a maioria obteve seu diploma de nível superior em cursos associados às profissões regulamentadas, reforçando o legado da matriz profissionalizante de ensino. Os dez cursos com maior representação de graduados são todos de profissões regulamentadas e agregam 67,5\% do total (Direito, Administração, Pedagogia, Engenharias, Letras, Ciências Contábeis e Atuariais, Medicina, Ciências Econômicas, Comunicação Social, Odontologia). Somando-se a esses os graduados nos cursos de Psicologia, Biologia e Enfermagem, que também são de profissões regulamentadas, temos $73, \%$ do total do estoque de mão-de-obra com mais de 23 anos de idade e formação superior. 
Tabela 2 - Pessoas de 23 anos ou mais de idade com curso superior (graduação, mestrado ou doutorado) - Brasil - 2000

\begin{tabular}{|c|c|c|c|c|}
\hline \multirow[t]{2}{*}{ Curso mais elevado concluído } & \multicolumn{4}{|c|}{ Pessoas de 23 anos ou mais de idade, com curso superior } \\
\hline & Total & $\%$ Total & \% Graduação & $\begin{array}{c}\text { \% Graduação } \\
\text { Acumulado }\end{array}$ \\
\hline Total & 5.830 .715 & $100 \%$ & - & - \\
\hline Graduação - Total & 5.526 .214 & $94,8 \%$ & $100,0 \%$ & - \\
\hline 1 Direito & 658.693 & $11,3 \%$ & $11,9 \%$ & $11,9 \%$ \\
\hline 2 Administração & 640.273 & $11,0 \%$ & $11,6 \%$ & $23,5 \%$ \\
\hline 3 Pedagogia & 576.699 & $9,9 \%$ & $10,4 \%$ & $33,9 \%$ \\
\hline 4 Engenharia & 433.182 & $7,4 \%$ & $7,8 \%$ & $41,8 \%$ \\
\hline 5 Letras & 366.992 & $6,3 \%$ & $6,6 \%$ & $48,4 \%$ \\
\hline 6 Ciências Contábeis e Atuariais & 303.681 & $5,2 \%$ & $5,5 \%$ & $53,9 \%$ \\
\hline 7 Medicina & 230.715 & $4,0 \%$ & $4,2 \%$ & $58,1 \%$ \\
\hline 8 Ciências Econômicas & 193.551 & $3,3 \%$ & $3,5 \%$ & $61,6 \%$ \\
\hline 9 Comunicação Social & 180.208 & $3,1 \%$ & $3,3 \%$ & $64,9 \%$ \\
\hline 10 Odontologia & 144.317 & $2,5 \%$ & $2,6 \%$ & $67,5 \%$ \\
\hline 11 Educação Física & 144.130 & $2,5 \%$ & $2,6 \%$ & $70,1 \%$ \\
\hline 12 Psicologia & 137.728 & $2,4 \%$ & $2,5 \%$ & $72,6 \%$ \\
\hline 13 Matemática & 129.978 & $2,2 \%$ & $2,4 \%$ & $74,9 \%$ \\
\hline 14 Ciências da Computação & 115.407 & $2,0 \%$ & $2,1 \%$ & $77,0 \%$ \\
\hline 15 História & 112.382 & $1,9 \%$ & $2,0 \%$ & $79,0 \%$ \\
\hline 16 Biologia & 105.258 & $1,8 \%$ & $1,9 \%$ & $80,9 \%$ \\
\hline 17 Artes & 104.822 & $1,8 \%$ & $1,9 \%$ & $82,8 \%$ \\
\hline 18 Outros de Ciências Biológicas & 90.046 & $1,5 \%$ & $1,6 \%$ & $84,5 \%$ \\
\hline 19 Enfermagem & 87.472 & $1,5 \%$ & $1,6 \%$ & $86,1 \%$ \\
\hline 20 Ciências e Estudos Sociais & 84.803 & $1,5 \%$ & $1,5 \%$ & $87,6 \%$ \\
\hline 21 Outros-Graduação & 685.877 & $11,8 \%$ & $12,4 \%$ & $100,0 \%$ \\
\hline Mestrado ou Doutorado & 304.500 & $5,2 \%$ & - & - \\
\hline
\end{tabular}

Fonte: IBGE, Censo Demográfico. Tabulação do autor. 
Formação e ocupação: contradição ou complementaridade

Mas nos perguntemos: Será que ensino universitário e profissão mantêm entre si uma contradição suplementar? Será que não há uma contradição lógica entre ensino universitário e ensino profissional, que precisa ser esclarecida ou, pelo menos submetida a uma análise informada dos dados? Será que profissão e ocupação já não são duas coisas distintas, fazendo com que os códigos das corporações profissionais sejam irrelevantes para a formação das gerações futuras?

Para responder a essas indagações, e a partir de um ponto de vista muito específico - qual seja, o da formação em nível superior -, tentaremos entender como se dá o diálogo entre o mundo da educação e o mundo do trabalho no Brasil. Não se trata, aqui, de mapear, ou discutir, as diferentes contribuições teóricas ao estudo das profissões. Muito menos se pretende definir se as profissões regulamentadas podem, ou não, ser identificadas como categorias ocupacionais diferenciadas ou mais organizadas. É importante esclarecer também, sem querer entrar em definições conceituais, que, até o momento, a principal unidade de análise foram as profissões regulamentadas; no que se segue - mais especificamente ao relacionarmos educação superior com mercado de trabalho - a unidade de análise passa a ser as ocupações.

Para situar melhor o universo em que se dá esse diálogo, registre-se que o Cadastro Brasileiro de Ocupações - CBO, ${ }^{15}$ utilizado pelo IBGE no levantamento e classificação das informações relativas ao mercado de tra-

15 A Classificação Brasileira de Ocupações - CBO é o documento normalizador do reconhecimento, da nomeação e da codificação dos títulos e conteúdos das ocupações do mercado de trabalho brasileiro. É ao mesmo tempo uma classificação enumerativa e uma classificação descritiva. A estrutura da CBO pressupõe somente um nível de competência possível por ocupação, família, subgrupo, subgrupo principal e grande grupo ocupacional. A CBO trabalha com 10 grandes grupos (GG), 47 sete subgrupos principais (SGP), 192 subgrupos (SG), 596 grupos de base ou famílias ocupacionais (SG), onde se agrupam 2.422 ocupações e cerca de 7.258 títulos sinônimos. 
balho, contabiliza a existência de 2.422 ocupações; o Censo da Educação Superior, de 2004, apresenta 485 diferentes denominações para um total de 18.644 cursos de graduação (aí incluídas as licenciaturas e os de tecnólogos). ${ }^{16}$ Observa-se, portanto, o grande número de ocupações, ou de denominações de ocupações representadas pelos cursos, existentes no país vis-à-vis o baixo número de profissões regulamentadas. Isso indica quanto o mercado de trabalho é complexo, dinâmico e diferenciado e quanto a economia moderna, apesar da crescente importância do conhecimento especializado na sociedade contemporânea, não se restringe às ocupações regulamentadas, ou seja, às profissões.Além disso, para melhor visualizar o universo no qual se inserem nossos formandos, recorreremos à análise das informações sobre a condição de ocupação do Censo Demográfico de 2000.

A forte influência da matriz profissionalizante para a escolha da carreira no Brasil poderia levar-nos a suspeitar que existiria uma forte relação entre o curso concluído e a atividade profissional exercida pelo formado. Ou seja, que aqueles que terminaram um curso superior estariam, predominantemente, trabalhando na profissão escolhida e não distribuídos em ocupações com pouco ou nenhuma afinidade com o título obtido. A análise das informações sobre a condição de ocupação do Censo Demográfico de 2000, no entanto, revelam o contrário. ${ }^{17}$

16 O Censo da Educação Superior apresenta os dados em três diferentes níveis de agregação: Áreas Gerais, Áreas Detalhadas e Programas e/ou Cursos. No caso de Administração, por exemplo, existem 46 diferentes denominações; Comunicação Social compreende 6 diferentes cursos de Jornalismo e Redação e 5 de Marketing e Publicidade.

17 Para definir as áreas típicas de atuação ou de competência das profissões tivemos que usar diferentes fontes, metodologias e critérios uma vez que nem todas as profissões/ocupações têm fronteiras claramente caracterizadas como, por exemplo, os profissionais da medicina. No extremo oposto, tem-se os Licenciados que não puderam ser correlacionados, tendo em vista a forma como as ocupações são identificadas no Censo Demográfico. 


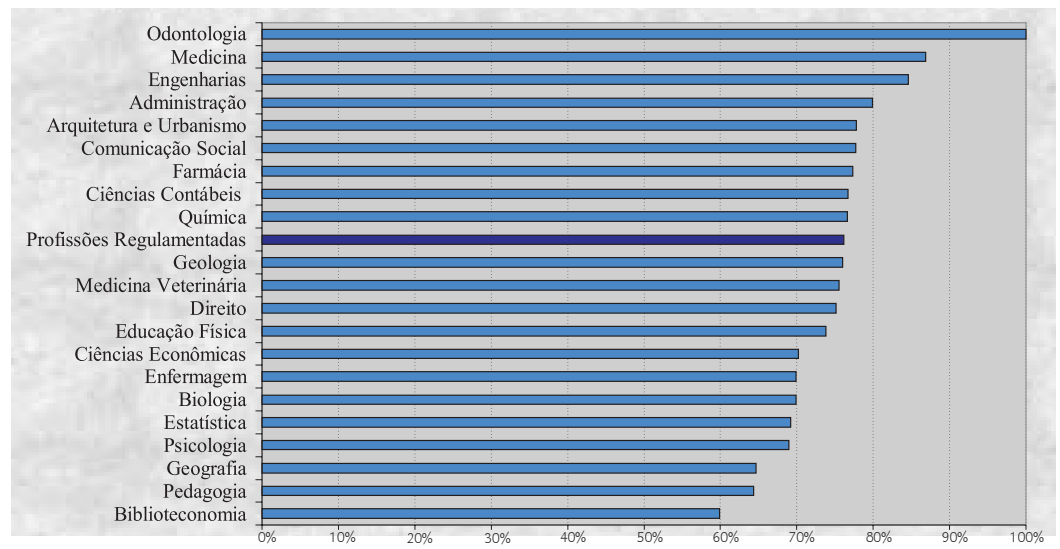

Gráfico 2 - Percentagem de pessoas de 23 anos ou mais de idade com trabalho remunerado segundo o curso de graduação - Brasil - 2000. Fonte: IBGE, Censo Demográfico. Tabulação do autor.

Mais importante, no entanto, é perceber que, se excluirmos medicina, mais da metade $(53,96 \%)$ das pessoas com nível superior nas áreas acima consideras e ocupadas exerciam trabalhos diversos, não necessariamente correspondentes às áreas em que se formaram ${ }^{18}$ (veja no gráfico 3).

Apenas pouco mais da metade das pessoas formadas em Direito, curso com forte viés profissionalizante, exerciam ocupações na área de formação. Proporção semelhante registra-se em relação aos formados em

18 Cláudio Moura e Castro já havia alertado em trabalho anterior que "pesquisas a partir dos dados da RAIS mostram que nas áreas sociais e humanidades, mais de $70 \%$ dos graduados não exercem a ocupação com o mesmo nome do diploma; há muitas áreas onde as proporções de graduados trabalhando na ocupação fica abaixo de $10 \%$ nas economias que se modernizam, há um crescimento extraordinário das ocupações onde se requer gente educada no nível superior, mas pouco importa em que se formaram. Essas ocupações existem aos milhões no setor terciário, na administração, na compra, venda, gerência, comunicações e uma infinidade de outras onde alguém com o diploma superior facilmente aprende o necessário para um desempenho adequado, após curto período de adaptação". Cláudio Moura Castro, "Provão: como entender o que dizem os números", mimeo, circulado em reunião de 15/2/2001, no INEP, com o objetivo de aprimorar o Projeto de Avaliação do Ensino Superior. O autor baseia-se em estudo de Reynaldo Fernandes e Renata Del Tedesco Narita, "Instrução Superior e Mercado de Trabalho no Brasil". São Paulo, Universidade de São Paulo-IPE, 1999. 
Sociologias, Porto Alegre, ano 9, no 17, jan./jun. 2007, p. 190-215

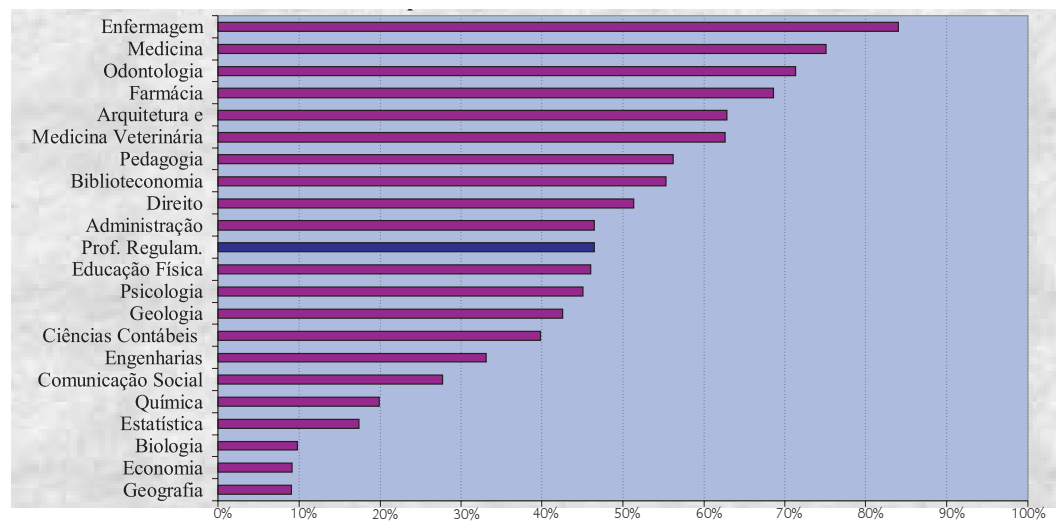

Gráfico 3 - Percentagem de pessoas de 23 anos ou mais de idade trabaIhando em área* à formação - Brasil - 2000.

Fonte: IBGE, Censo Demográfico. Tabulação do autor.

Nota: * As ocupações correspondentes à formação estão no ANEXO.

Pedagogia e Biblioteconomia, respectivamente 56,2\% e 55,3\%. Chama a atenção também o fato de que dois terços dos formados nas engenharias não trabalhavam na área correspondente ao título superior. A exceção são os formados em medicina, os quais 75\% trabalhavam na área correspondente à formação. Ou seja, há um grande contingente de pessoas com curso superior que não trabalham na área em que se formaram - com exceção daqueles que fizeram medicina, odontologia e enfermagem, setor altamente profissionalizado.

Para exemplificar a diversidade das ocupações, tomando apenas as ocupações dos formados nas chamadas profissões imperiais, ou seja, medicina, direito e engenharias, e que, por isso, podem ser consideradas arquétipos da matriz de ensino profissionalizante discutida neste trabalho, chamamos a atenção para a diversidade de ocupações exercidas: vendedores, gerentes, contadores e auditores, escriturários etc. Veja no anexo deste documento as outras ocupações dos formados em Medicina, Administração, Contábeis, Comunicação Social, Direito e Engenharia 
Se a observação da empregabilidade dos formados já revela uma baixa relação entre formação e profissão (exceção sempre feita à medicina), o quadro de diversidade no mercado de trabalho é reforçado quando a análise se detém na configuração das ocupações no Brasil, ou seja, a análise da formação das pessoas dentro das ocupações. Exemplo neste sentido pode ser encontrado na elite dirigente tanto do setor público como do setor privado brasileiro.

Como pode ser observado, este recorte ocupacional dos Dirigentes do Setor Público, os Dirigentes Gerais da Administração Pública, os Dirigentes de Produção e Operações da Administração Pública e dos Dirigentes das Áreas de Apoio da Administração Pública revela que expressiva parcela do contingente de pessoas que exercem tais ocupações não têm curso superior, respectivamente $67,9 \%, 70,7 \%$ e $56,9 \%$. No front privado, e ainda em relação à elite dirigente, a situação não é muito diferente: no curso mais elevado: $73 \%$ dos dirigentes de empresas e empregadores do setor privado não possuem nenhum curso.

Ou seja, 72,7\% da elite gestora do Estado brasileiro não tem a educação que hoje seria considerada mínima para assumir postos vitais. Trata-se de um número drástico que dispensa comentários como toda boa tragédia.

Como vimos anteriormente, cerca de dois terços de nossos estudantes, mais especificamente de nossos concluintes, estão associados às profissões regulamentadas, para as quais existem corporações ativas, embora isso tenha diminuto significado na vida real do trabalho, na vida depois da saída da Universidade.

Observamos que também tem pouco significado o volume de educação profissional porque o estoque de dirigentes brasileiros é constituído majoritariamente por pessoas que não estão ou não estiveram na educação superior.

Em verdade, verificamos que existe uma baixa relação entre a área na qual o estudante se forma e sua atividade profissional. De acordo com os 
Tabela 3 - Instrução das pessoas de 23 anos ou mais de idade, ocupadas como membros superiores do poder público, diretores, gerentes e dirigentes do setor privado - Brasil - 2000

\begin{tabular}{|c|c|c|c|c|}
\hline \multirow{3}{*}{ Ocupação } & \multicolumn{4}{|c|}{$\begin{array}{c}\text { Pessoas de } 23 \text { anos ou mais de idade, ocupadas como membros } \\
\text { superiores do poder público, diretores, } \\
\text { gerentes e dirigentes do setor privado - Brasil - } 2000\end{array}$} \\
\hline & \multirow[b]{2}{*}{ Total (T) } & \multicolumn{2}{|c|}{ Nível de instrução } & \multirow[b]{2}{*}{$\begin{array}{l}\% \text { sem ensino } \\
\text { superior }(A)(T\end{array}$} \\
\hline & & $\begin{array}{l}\text { Com superior } \\
\text { completo (Grad, } \\
\text { Mestr, Dout.) }\end{array}$ & $\begin{array}{l}\text { Sem ensino } \\
\text { superior }(A)\end{array}$ & \\
\hline Total & 2.660 .900 & 725.618 & 1.935 .282 & 72,7 \\
\hline Setor Público & 153.035 & 49.364 & 103.671 & 67,7 \\
\hline $\begin{array}{l}\text { Dirigentes Gerais da Adm } \\
\text { Pública }\end{array}$ & 7.026 & 2.254 & 4.772 & 67,9 \\
\hline $\begin{array}{l}\text { Dirigentes de Produção e } \\
\text { Operações }\end{array}$ & 14.641 & 4.292 & 10.349 & 70,7 \\
\hline Dirigentes das Áreas de Apoio & 82.781 & 35.682 & 47.099 & 56,9 \\
\hline $\begin{array}{l}\text { Dirigentes e Adm de Org. de } \\
\text { interesse público }\end{array}$ & 20.764 & 3.362 & 17.402 & 83,8 \\
\hline $\begin{array}{l}\text { Legisladores e Ministros de } \\
\text { Tribunais }\end{array}$ & 27.823 & 3.773 & 24.050 & 86,4 \\
\hline Setor Privado & 2.507 .865 & 676.254 & 1.831 .611 & 73,0 \\
\hline Diretores gerais & 20.966 & 13.537 & 7.429 & 35,4 \\
\hline $\begin{array}{l}\text { Dirigentes de empresas } \\
\text { (empregadores) }\end{array}$ & 348.803 & 110.170 & 238.633 & 68,4 \\
\hline $\begin{array}{l}\text { Diretores de áreas de produção, } \\
\text { operações, apoio }\end{array}$ & 158.335 & 90.361 & 67.974 & 42,9 \\
\hline $\begin{array}{l}\text { Gerente de produção e de } \\
\text { operações e de apoio }\end{array}$ & 1.979 .761 & 462.186 & 1.517 .575 & 76,7 \\
\hline
\end{tabular}

Fonte: IBGE. Censo Demográfico. Tabulação do autor 
dados do Censo Demográfico 2000, de 371 mil pedagogos existentes no Brasil, apenas $66,2 \%$ trabalhavam na área em que se formaram; dos mais de meio milhão de formados em administração apenas $46,4 \%$ trabalhavam na área; em comunicação social, uma área tão violenta na defesa dos seus títulos, para ser jornalista, descobrimos que apenas $27,7 \%$ trabalhavam na área; em direito apenas 51,2\%, com destaque para a área da saúde, na qual medicina apresenta uma participação das pessoas trabalhando na profissão na qual se formaram, muito mais intensa do que as já mencionadas.

Se assim é, precisamos aprender, precisamos concluir que as profissões regulamentadas, que tanto poder têm ante ao MEC, que tanto poder têm ante o sistema político e que tantos alunos atraem, até servem para formar quadros para as tais profissões regulamentadas. Até servem, mas não constituem a função final da educação superior brasileira de hoje.

Formação e ocupação: um problema de enfoque

Tomemos o problema por outro ângulo. Dos cerca de 5.830 milhões de pessoas, com mais de 23 anos de idade, com diploma superior no Brasil, observamos que $11 \%$ têm formação em administração; 11,3\% em direito, 9,9\% em pedagogia; 7,4\% em engenharias, em 6,3\% letras.

Registramos também que o número total de pessoas com mais de 23 anos de idade é, de aproximadamente, 91.500 milhões e que, portanto, estamos falando de cerca de 5.8 milhões com diploma superior, isto equivale a $6,37 \%$ desse total. Isso quer dizer que a discussão recente sobre a expansão da educação superior se pauta em duas proposições que são simultaneamente verdadeiras e diametralmente distintas. Primeiro, a de que já existem profissionais em excesso em algumas áreas. Segundo, a de que existem poucos estudantes universitários.

Essas proposições só podem existir porque a educação superior no Brasil está errada. É verdade que pode, até, existir um número grande, ou quem sabe excessivo de profissionais em algumas áreas, embora inexistam 
critérios internacionalmente validados para tal proposição. Mas é também verdade que não há universitários em número suficiente no Brasil.

Ou seja, a realidade contradiz o discurso feito pelas corporações e pelo governo. A realidade desautoriza os instrumentos de política para a educação quando, por exemplo, procura-se relacionar o número de vagas nas instituições de educação superior, por não considerar as elevadas taxas de migração interestadual e municipal existentes no país. ${ }^{19}$

O discurso, contudo, que não se faz, e a indagação que precisa ser feita são: para que serve ou o que representa, no mercado de trabalho, a educação superior no Brasil contemporâneo? Para que servem as profissões regulamentadas? Existem profissões regulamentadas em demasia?

O que se chama, no Brasil de profissão nada mais é que um conjunto de ocupações típicas do setor terciário. Por esta razão, o congresso brasileiro deveria abster-se de regulamentar essas "profissões", e nossos colegas, egressos das universidades brasileiras, deveriam também abster-se de procurar organizar as ocupações em torno de uma autoridade profissional. O acesso ao mercado de trabalho e ao conhecimento não é exclusivo das profissões. A educação superior no Brasil constitui um "prêmio" de renda em si mesmo, independentemente da eventual "profissão", desnecessitando, portanto do licenciamento estatal, das barreiras e monopólios legalmente construídos.

O que chamamos aqui de "prêmio" pode ser constatado, com o concurso dos dados da PNAD-Pesquisa Nacional por Amostra de Domicílios, na qual fica evidente que, independentemente da idade, o rendimento médio mensal dos portadores de diploma de nível superior é, sistematicamente, superior - e bem superior - ao daqueles que interromperam seus estudos no nível médio. Como se observa no gráfico abaixo, não só é sistematicamente maior, como para pessoas com 40-49 anos, o rendimento médio é o dobro.

19 A esse respeito ver, Consideraçôes sobre o Conceito de "Necessidade Social": Uma Nota Técnica, Enrico Martignoni e Leandro Molhano, Observatório Universitário, Documento de Trabalho no.46, abril de 2005. 


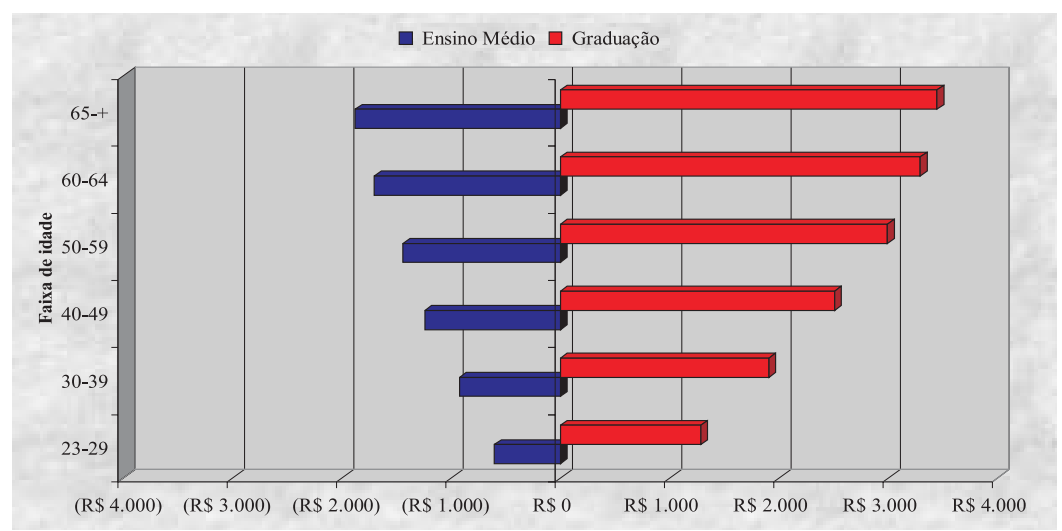

Gráfico 4 - Rendimento médio mensal em todos os trabalhos segundo o grupo etário e o nível de instrução - Brasil - 2000.

Fonte: IBGE, Censo Demográfico. Tabulação do autor.

Os mesmos dados evidenciam, ainda, que essa diferenciação existe não apenas em relação às pessoas ocupadas: o desemprego atinge de forma diferenciada os portadores de diploma universitário e aqueles que não foram expostos à educação superior e ao conhecimento formal adquirido neste nível educacional. Observe-se no gráfico 5 que a taxa de ocupação é maior para os que possuem ensino superior completo do que ensino médio, em todas as faixas etárias.

O mercado de trabalho valoriza fortemente a educação superior, embora a falta desta formação, como vimos no caso das elites dirigentes do país, não se constitua, de fato, em uma barreira à inserção neste mesmo mercado.

O paradoxo brasileiro talvez seja o efeito perverso de um sistema que se apóia no tripé formado pelas universidades, órgãos de classe e Estado. Educação é uma área consagrada de atuação do Estado, a qual autoriza a criação de cursos universitários. É também o Estado que reconhece e licencia as associações profissionais e o exercício profissional. 
Sociologias, Porto Alegre, ano 9, no 17, jan./jun. 2007, p. 190-215

Por isso, as duas afirmativas contraditórias - de que existem profissionais em excesso em algumas áreas, e estudantes de menos em todas as áreas - podem até ser simultaneamente verdadeiras, mas escondem o dilema estratégico brasileiro: como crescer rapidamente e desprofissionalizar o ensino universitário, de um lado, e como diversificá-lo de outro.

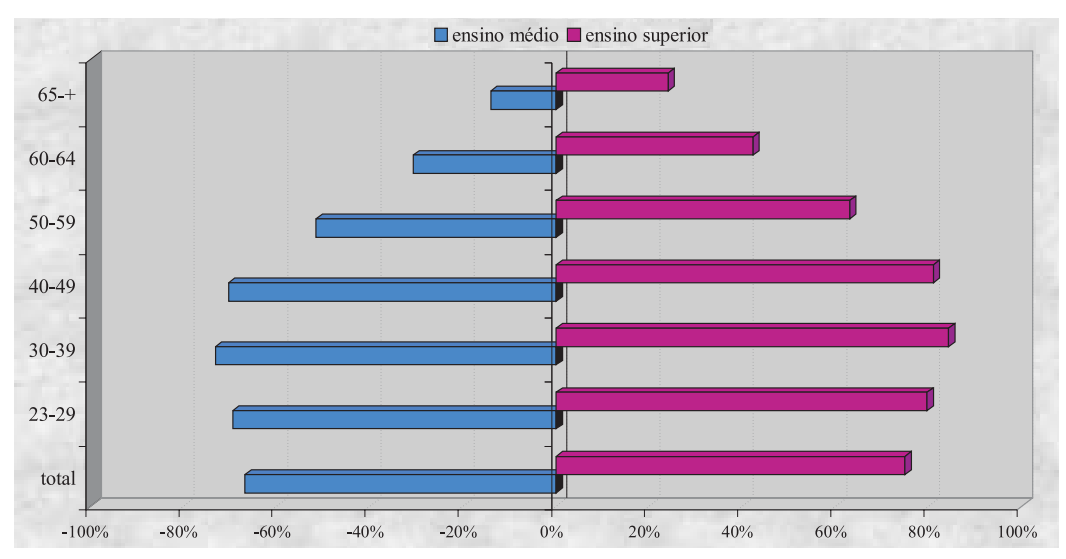

Gráfico 5 - Percentagem de pessoas de 23 anos ou mais com trabalho remunerado, segundo o nível de ensino - Brasil - 2000.

Fonte: IBGE, Censo Demográfico. Tabulação do autor.

\section{Conclusão}

Um comentário final: as questões abordadas ao longo deste ensaio parecem questionar apenas o modelo curricular. É, porém, fundamental registrar que, no cerne dessa discussão, está a própria definição do que se entende, ou deveria entender, por ensino universitário e Universidade. O ensino superior de massa, marca mundial contemporânea, há de enfrentar 
problemas impensados pela Universidade contemporânea. ${ }^{20}$ Primeiro, o financiamento do ensino universitário massificado acarretará custos desconhecidos por ter vicejado, até então, um sistema de elites. Os custos por alunos, custos por output, para usar outro termo, terão suas proporções alteradas daqui para a frente. Segundo, a demanda sobre a Universidade será exponencial porque o aprendizado tenderá a ser processo longo, com idas e vindas à Universidade, visto que as pessoas nunca mais estarão "prontas". Estarão sempre se aprontando. Terceiro, o crescimento e a multiplicação do conhecimento impedirão a existência da "universidade", no sentido que o termo assumiu historicamente. Existirá conhecimento demais para uma só instituição, qualquer instituição. Por isso, o conceito de Universidade precisará ser revisto. Quarto, os itens anteriores vão exigir que as instituições que hoje chamamos de universidades providenciem padrões de respostas às demandas do meio ambiente, que são incompatíveis com as organizações que conhecemos. Visto que o crescimento do conhecimento é superior aos recursos organizacionais, ninguém controlará, internacionalmente, a produção, reformulação e distribuição do conhecimento.

20 - Exemplos de debate recente sobre o tema, podem ser buscados em: Ronald Barnett, Realizing the University in an Age of Supercomplexity, The Society for Research into Higher Education \& Open University Press, Buckingham, 2000; Henry Etzkowitz e Loet Leydesdorff, Universities and Global Knowledge Economy: A Triple Helix of University-Industry-Government Relations, Science, Technology and the International Political Economy Series, Continuum, N. York, paperback edition, 2001, Frank Newman, Lara Courtier, James Scurry, The Future of Higher Education: Rethoric, Reality and the Risks of the Market, Jossey-Bass, San Francisco, 2004. Reflexões mais personalizadas, nem por isso menos densas, podem ser vistas em Harold Shapiro, A Larger Sense of Purpose: Higher Education and Society, Princeton University Press, 2005; Harry R. Lewis, Excellence without a Soul: How a Great University Forgot Education, Public Affairs, New York, 2006. Pelo lado das relações com o mercado e o futuro, ver Derek Bok, Universities in the Market Place: The Commercialization of Higher Education, Princeton University Press, 2003; Douglas Priest e Edward St. John (Eds.), Privatization and Public Universities, Indiana University Press, 2006, David L. Kirp, Shakespeare, Einstein, and the Bottom Line: The Marketing of Higher Education, Harvard U. Press, 2004; Richard Hersh e John Merrow, Declining by Degrees: Higher Education at Risk, Palgrave MacMillan, N. York, 2005. Ver também, Higher Education in the World, 2006: The Financing of Universities, GUNI Series on the Social Commitment of Universities, Palgrave MacMillan, N. York, 2006. 
Todos os pontos discutidos neste texto apontam para a necessidade de um projeto estratégico sistêmico, de médio e longo prazos para a educação superior no Brasil. Um projeto que ressalte a preocupação com a formação continuada e o desenvolvimento de um ensino capaz de proporcionar a empregabilidade dos estudantes em uma economia baseada na aquisição de habilidades.

\section{Referências}

BARNETT, Ronald. Realizing the University in an Age of Supercomplexity, The Society for Research into Higher Education \& Open University Press. Buckingham, 2000;

BRENNAN et al. What Kind of University? International Perspective on Knowledge, Participation and Governance. London: The Society for Research into Higher Education, Open University Press, 1999

BOK, Derek. Our Underachieving Colleges: A Candid Look at How Much Students Learn and Why they Should be Learning More, Princeton University Press. Princeton, 2006.

BOK, Derek .Universities in the Market Place: The Commercialization of Higher Education, Princeton University Press, 2003.

BOWEN, Willian et al. Equity and Excellence in American Higher Education, University of Virginia Press, 2005.

BURTON R. Clark (Ed.), The Research Foundations of Graduate Education: Germany, Britain, France, United States, Japan, University of California Press, Berkeley, 1993.

CHRISS Golde, George Walker (Eds.) Envisioning the Future of Doctoral Education: Preparing Stewards of the Discipline, The Carnegie Foundation for the Advancement of Teaching, Jossey-Bass, San Francisco, 2006

COHEN, Arthur e BRAWER, Florence. The American Community College. San Francisco: Jossey Bass, 1996. 
DOUTHAT, Ross. Gregory Privilege: Harvard and the Education of the Ruling Class, Hyperion, N.York, 2005.

ETZKOWITZ, Henry e LEYDESDORFF, Loet .Universities and Global Knowledge Economy: A Triple Helix of University-Industry-Government Relations, Science, Technology and the International Political Economy Series, Continuum, N. York, paperback edition, 2001,

FERNANDES, Reynaldo e NARITA, Renata Del Tedesco. Instrução Superior e Mercado de Trabalho no Brasil. São Paulo, Universidade de São Paulo - IPE, 1999.

GUNI Series on the Social Commitment of Universities. Higher Education in the World, 2006: The Financing of Universities, Palgrave MacMillan, N. York, 2006.

HERSH, Richard e MERROW, John. Declining by Degrees: Higher Education at Risk, Palgrave MacMillan, N. York, 2005.

LEWIS, Harry R. Excellence without a Soul: How a Great University Forgot Education, Public Affairs, New York, 2006.

LOSCO, Joseph e LIFE, Brian (Org.) Higher Education in Transition: the Challenges of the New Millennium. Westport, Connecticut: Bergin \& Garvey, 2000.

KIRP, David L. Shakespeare, Einstein, and the Bottom Line: The Marketing of Higher Education, Harvard U. Press, 2004.

MARTIGNONI, Enrico e MOLHANO, Leandro. Considerações sobre o Conceito de Necessidade Social: uma nota técnica. Rio de Janeiro: Observatório Universitário, Documento de Trabalho n⿳⺈⿴囗十一, abril de 2006.

MENEZES, Luiz Carlos de. Universidade sitiada. São Paulo: Editora Fundação Perseu Abramo, 2000.

NEWMAN, Frank; COURTIER, Lara e SCURRY, James. The Future of Higher Education: Rethoric, Reality and the Risks of the Market, Jossey-Bass, San Francisco, 2004.

NUNES, Edson et al. Futuros Possíveis, Passados Indesejáveis: Selo de Qualidade da $\mathrm{OAB}$, Provão e Ensino Superior no Brasil. Rio de Janeiro: Editora Garamond, 2000. 
Sociologias, Porto Alegre, ano 9, no 17, jan./jun. 2007, p. 190-215

NUNES, Edson et al. Teias de Relações Ambíguas: regulação e ensino superior. Brasília: Inep, 2002;

NUNES, Edson. A Reforma Universitária no "Quadro-Negro", em Custo Brasil Soluções para o Desenvolvimento, ano 1, no. 2, abril/maio de 2006.

NUNES, Edson e MOLHANO, Leandro . A outra reforma universitária: para a sociedade do conhecimento. In: VELLOSO, João Paulo dos Reis(org) . Novo Modelo de Educação para o Brasil, José Olympio Editora, Rio, 2004, p. 152.

O'BRIEN, George. All the Essential Half-Truths about Higher Education. Chicago: The University of Chicago Press, 1998.

PRIEST, Douglas e JOHN, Edward St. (Eds.) Privatization and Public Universities, Indiana University Press, 2006 ,

SHAPIRO, Harold. A Larger Sense of Purpose: Higher Education and Society, Princeton U. Presss, 2005

TUROW, One L.: The Turbulent True Story of a First Year at Harvard Law School, Warner Books, N.York, 1977 e 1988. 
Sociologias, Porto Alegre, ano 9, no 17, jan./jun. 2007, p. 190-215

\section{Resumo}

Este artigo examina a relação entre a formação de nível superior e a ocupação profissional, a partir dos dados do Censo Demográfico de 2000 (IBGE), com ênfase nas ocupações relacionadas às profissões regulamentadas. Verifica a existência de grande discrepância entre o diploma formal e a ocupação efetiva dos graduados. Considera que a não correspondência entre formação e ocupação deve-se, fundamentalmente, ao modelo educacional, historicamente amarrado às profissões regulamentadas, que não mais atende à realidade efetiva da sociedade brasileira.

Palavras-chave: Ensino Superior, mercado de trabalho, ocupação no mercado de trabalho.

Recebido: 04/01/07

Aceite final: 26/02/07 
Sociologias, Porto Alegre, ano 9, ㄲo 17, jan./jun. 2007, p. 346-352

College education, corporation, and profession: Brazilian dilemmas and paradoxes

Edson Nunes \& Márcia Marques de Garvalho

This article examines the relationship between higher education and professional occupation, based on data from the 2000 Demographic Census (IBGE), stressing occupations related to regulated professions. A large gap is seen between having a formal diploma and the real occupation of graduates. It considers that noncorrespondence between education and occupation is due mainly to the educational model, historically tied to regulated professions, which no longer meets the reality of Brazilian society.

Key words: Higher education, job market, occupation in the job market. 